\title{
EFEITOS DA DEFORMAÇÃO PLÁSTICA SEVERA E DA HIDROGENAÇÃO NA MICROESTRUTURA DA LIGA Ti-40Nb*
}

Rafael de Araujo Silva ${ }^{1}$

Renato Belli Strozi2

Daniel Rodrigo Leiva ${ }^{3}$

Walter Jose Botta Filho ${ }^{4}$

\section{Resumo}

As ligas $\beta$-Ti têm sido consideradas materiais com potencial para armazenagem de hidrogênio no estado sólido. A adição de elementos de liga estabilizadores da fase $\beta$, tal como o $\mathrm{Nb}$, retém esta fase metaestável em temperatura ambiente. Neste trabalho a liga Ti-40Nb (at.\%) foi produzida via fusão a arco e suas características microestruturais foram caracterizadas visando avaliar os efeitos da aplicação da deformação plástica severa (SPD, severe plastic deformation) e da hidrogenação. A laminação a frio sob atmosfera de Argônio foi a técnica de SPD escolhida. Os resultados principais mostraram que é possível hidrogenar a liga fundida Ti-40Nb em temperatura ambiente após laminação a frio. Os efeitos da deformação plástica severa na microestrutura da liga, como a introdução de discordâncias, foram importantes para o aperfeiçoamento da cinética de absorção em temperatura ambiente $\left(25^{\circ} \mathrm{C}\right)$. Após a dessorção da fase hidreto (CFC) a microestrutura volta a ser constituída pelas fases $\beta$ (CCC) e $\alpha$ " (ortorrômbica).

Palavras-chave: Ligas $\beta$ do sistema Ti-Nb; Fusão a arco; Deformação plástica severa; Armazenamento de hidrogênio.

\section{EFFECTS OF SEVERE PLASTIC DEFORMATION AND HYDROGENATION IN MICROSTRUCTURE OF Ti-40Nb ALLOY}

\section{Abstract}

The $\beta$-Ti alloys have been considered as potential materials for solid state hydrogen storage. The addition of $\beta$-Ti stabilizing elements such as $\mathrm{Nb}$ can retain a metastable $\beta$ phase at room temperature. In this study, the arc-melting method was applied to produce the Ti-40Nb (in at.\%) alloy. The main aim of this work is to evaluate the hydrogen absorption properties of $\mathrm{Ti}-40 \mathrm{Nb}$ alloy processed by severe plastic deformation (SPD). The cold rolling under argon atmosphere was the chosen as SPD method. The main results showed the possibility to introduce hydrogen in the Ti$40 \mathrm{Nb}$ alloy at room temperature due to the combined processings of melting and cold rolling. The FCC hydride phase returns to a microstructure comprising BCC $\beta$ phase and orthorhombic $\alpha$ " phase after desorption.

Keywords: Ti-Nb $\beta$ alloy; Arc-melting; Severe plastic deformation; Hydrogen storage.

1 Doutor em Engenharia de Materiais e de Processos Químicos e Metalúrgicos, Pós-doutorando, DEMa,UFSCar, São Carlos, São Paulo, Brasil.

2 Mestrando em Engenharia de Materiais, PPG-CEM/UFSCar, São Carlos, São Paulo, Brasil.

3 Engenheiro de Materiais, Professor Adjunto, Departamento de Engenharia de Materiais, Universidade Federal de São Carlos, São Paulo, Brasil.

4 Professor Titular, Departamento de Engenharia de Materiais, Universidade Federal de São Carlos, São Paulo, Brasil. 


\section{INTRODUÇÃO}

As ligas do sistema Ti-Nb são usadas em aplicações aeroespaciais e biomédicas, também sendo utilizadas como supercondutores [1,2]. Várias composições das ligas $\beta-\mathrm{Ti}$ são embasadas no sistema Ti-Nb, tipicamente contendo de 11,4 a 25,6 at.\% $\mathrm{Nb}$ [1]. A superelasticidade destas ligas ocorre devido à transformação de fase de $\beta$ para $\alpha$ " (martensítica) e vice-versa [3]. Além destas aplicações, as ligas $\beta-T i$ têm sido consideradas como materiais com potencial para armazenagem de hidrogênio no estado sólido [4,5]. Assim, o principal objetivo deste trabalho é caracterizar as mudanças microestruturais da liga Ti-40Nb (at.\%) como fundida devido aos processamentos por deformação plástica severa (SPD) e hidrogenação.

$\mathrm{Na}$ temperatura ambiente, o Titânio puro tem uma estrutura cristalina hexagonal (fase $\alpha$ ) e para temperaturas maiores do que $882{ }^{\circ} \mathrm{C}$ a fase estável é a $\beta$, cuja estrutura cristalina é cúbica de corpo centrado (CCC) [6]. Além das fases $\alpha$ e $\beta$ o sistema Ti-Nb exibe as fases metaestáveis martensíticas $\alpha^{\prime}$ (hexagonal) e $\alpha$ " (ortorrômbica) e a fase $\omega$ (hexagonal) $[1,2,7]$. A temperatura de início da reação martensítica (Ms) aumenta com a redução do teor de Nióbio e tornando-se maior que a temperatura ambiente quando o teor de Nióbio é inferior a 25,5 at.\% [8]. Em resfriamento de têmpera a partir do campo $\beta$, com composições entre 5 e 11 at.\% $\mathrm{Nb}$, ocorre a formação de $\alpha^{\prime}$ independentemente da taxa de têmpera, entre 11 e 28 at.\% $\mathrm{Nb}$ ocorrerá a formação de $\alpha$ ", sendo que para concentrações acima de 38,5 at.\% $\mathrm{Nb}$ não ocorre a transformação atérmica de $\beta$ para $\omega$ sob altas taxas de resfriamento e a fase $\beta$ torna-se retida [7]. Metais de transição como Mo, $\mathrm{V}$ and $\mathrm{Nb}$ estabilizam a fase $\beta$ [2] do sistema Ti-Nb que tem apresentado interessantes propriedades de armazenamento de hidrogênio $[4,5]$. Os estudos das propriedades de hidrogenação das fases de equilíbrio $\alpha$ e $\beta$ e das fases metaestáveis $\alpha$, $\alpha$ " e $\omega$ de maneira isolada não fazem parte do escopo deste trabalho.

Devido ao alto ponto de fusão do Nióbio $(2750 \mathrm{~K})$ a fusão a arco pode ser empregada com sucesso para a obtenção de ligas do sistema Ti-Nb [9]. Outros métodos de fabricação são a sinterização [4] e a moagem de alta energia [10]. Quando estas ligas refratárias se solidificam rapidamente, elas exibem uma complexa rede de dendritas e microsegregação de elementos de liga [9].

A aplicação de deformação plástica severa (SPD), tal como a laminação a frio introduz defeitos, como discordâncias e maclação mecânica, ativa os mecanismos de refinamento de grãos e favorece a formação da fase $\alpha$ " nas ligas $\beta$ do sistema Ti$\mathrm{Nb}$ [1]. O refinamento microestrutural, promovido pela SPD, eleva a densidade de contornos de grão que juntamente com os contornos de fases são locais preferenciais para a difusão do Hidrogênio.

\section{MATERIAIS E MÉTODOS}

Quanto à composição química da liga, a razão entre os percentuais atômicos foi mantida fixa $(\mathrm{Ti} / \mathrm{Nb}=1,5)$. A liga Ti-40Nb (at.\%) foi produzida por fusão a arco a partir dos pós elementares de Titânio e Nióbio. O Titânio e o Nióbio utilizados neste trabalho são da fabricante SIGMA-ALDRICH, o Titânio com 325 mesh e pureza de $99,98 \%$ e o Nióbio com granulometria menor do que $45 \mu \mathrm{m}$ e pureza de $99,8 \%$.

Para os procedimentos de fusão, primeiro os pós foram pesados respeitando a proporção de massa atômica para a obtenção da liga Ti-40Nb (at.\%) e então misturados dentro de uma cuba de moagem com 3 bar de Argônio, utilizando o 
moinho planetário Fritsch Pulverisette 6 operado a 400 rpm por 1 hora. Os pós foram manuseados no interior de uma glove-box, onde uma mistura de massa igual a $10 \mathrm{~g}$ foi pré-compactada sob atmosfera de Argônio utilizando uma matriz cilíndrica com diâmetro interno de 16,2 mm. A compactação final do corpo de prova ocorreu ao ar em uma prensa hidráulica através da apliçação de uma carga de $10 \mathrm{t}$, seguindo para a etapa de fusão a arco. No forno de fusão a arco o lingote foi fundido por cinco vezes para homogeneizar a composição química da liga. Para a caracterização das propriedades de absorção de hidrogênio do material como fundido (FA) foram utilizadas as partículas oriundas da fragmentação do lingote em um minilaminador instalado dentro da glove-box. Outra parte do lingote foi submetida à deformação plástica severa via laminação a frio sob atmosfera de Argônio. A frequência de operação foi fixada em $40 \mathrm{~Hz}$ e os números de passes realizados foram 40 (CR40) e 80 (CR80).

A capacidade gravimétrica e as propriedades cinéticas de absorção foram caracterizadas utilizando um aparato volumétrico tipo Sievert pressurizado com 20 bar de Hidrogênio (4.5 FID) e temperaturas de absorção de $300^{\circ} \mathrm{C}$ para o material como fundido e temperatura ambiente para o material fundido e laminado. Todos os ensaios foram realizados no campo $\alpha+\beta$ [6] utilizando $150 \mathrm{mg}$ de massa de amostra.

Para a difração de raios $X$ foram usados radiação do $\operatorname{CuK\alpha }(\lambda=1,5418 \AA)$, faixa angular de 5 a $90^{\circ}$, passo de varredura de $0,032^{\circ}$ a $1 \mathrm{~s} /$ passo, sendo as varreduras realizadas em um difratômetro Siemens modelo D5005 operado a $40 \mathrm{~mA}$ e $40 \mathrm{kV}$ em temperatura ambiente. Os tamanhos de cristalito $(t)$ e as microdeformações (e) foram obtidos do alargamento do pico principal de DRX [11,12] e também através dos gráficos de Williamson-Hall (W-H), ambos especificamente para a fase $\beta$, como auxílio do Software X'Pert HighScore Plus versão 3.0. As imagens de microscopia eletrônica de varredura (MEV), as análises de espectroscopia de energia dispersiva (EDS) e os mapas de composição química foram usados para caracterizar o material como fundido. A temperatura de início da reação martensítica foi calculada embasada na literatura [8] a partir do percentual médio de $\mathrm{Nb}$ obtido de 5 regiões dendríticas. A estabilidade das fases foi avaliada através da calorimetria diferencial de varredura (DSC). A estabilidade térmica dos hidretos formados após a absorção de hidrogênio e suas capacidades gravimétricas foram obtidas através das análises de DSC e termogravimétrica (TGA), respectivamente, usando massa de amostra de $10 \mathrm{mg}$, com taxa de aquecimento de $10 \mathrm{~K} / \mathrm{min}$ sob fluxo de Argônio de $25 \mathrm{~mL} / \mathrm{min}$. Um espectrômetro de massa quadrupolo (QMS) acoplado ao STA-449C possibilitou a identificação dos gases evoluídos.

\section{RESULTADOS E DISCUSSÃO}

A figura 1 mostra os aspectos morfológicos das partículas do lingote fragmentado e após laminação a frio de 40 e 80 passes. Observa-se através da escala da figura 1a que as partículas de material fundido apresentam tamanho maior do que $1 \mathrm{~mm}$ e que após a laminação das mesmas, ocorreu a formação de flocos sobrepostos em camadas. Algumas trincas, que favorecem a entrada do hidrogênio no material [10], também foram observadas na figura 1.

Após os ciclos térmicos de fusão a arco, as fases caracterizadas na microestrutura bruta de fusão via MEV (figura $2 a$ e $2 b$ ) e por DRX (figuras 3, 4 e 5) mostram que 0 material fundido apresenta as fases $\beta$ (CCC) e a fase ortorrômbica ( $\alpha$ "), não podendo ser descartada a presença das fases $\alpha, \alpha^{\prime}$ e $\omega$ (hexagonais). Para a composição 
química adotada, após o resfriamento do lingote em um cadinho de cobre refrigerado a água (no forno de fusão a arco), era esperado que a microestrutura final fosse majoritariamente formada pela fase $\beta$ e apresentasse apenas traços da fase $\alpha$ (HCP). Contudo, as heterogeneidades da composição química devido à segregação do Nióbio durante a etapa de solidificação do lingote conduziram a uma microestrutura final complexa [9]. Os resultados nas figuras $2 c$ e $2 d$ mostram os mapas de composição química sobrepostos dos elementos Titânio e Nióbio, revelando que as regiões dendríticas estão mais ricas em Titânio (regiões em verde).

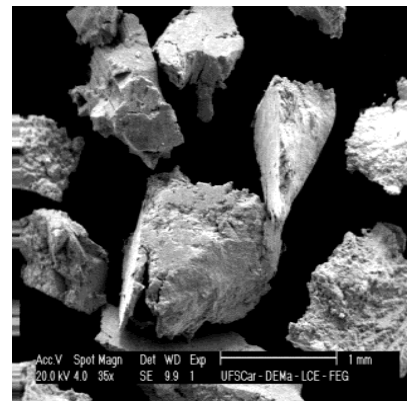

(a)

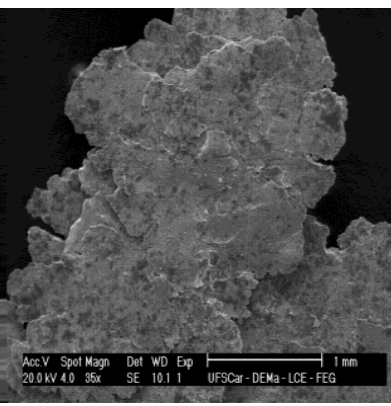

(b)

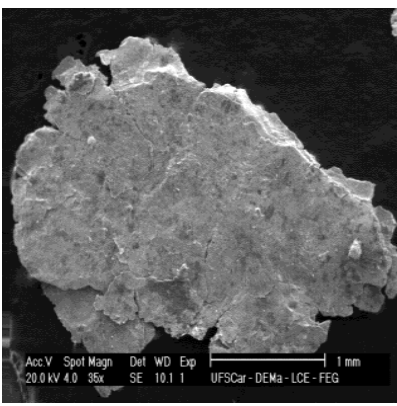

(c)

Figura 1. Microscopia eletrônica de varredura de: (a) partículas do lingote fragmentado, (b) material após 40 passes de laminação a frio e (c) após 80 passes de laminação a frio.

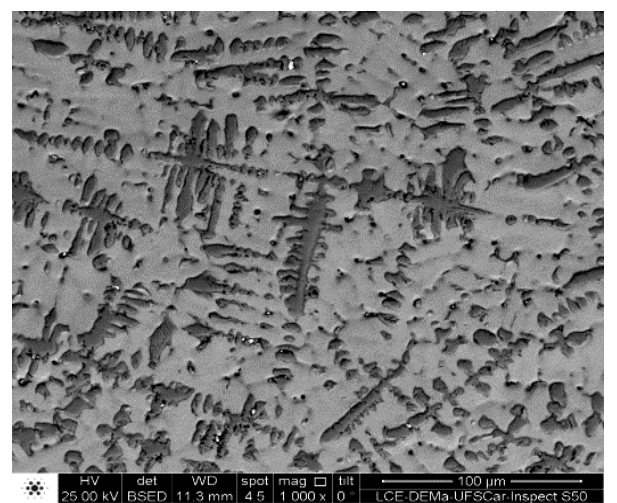

(a)

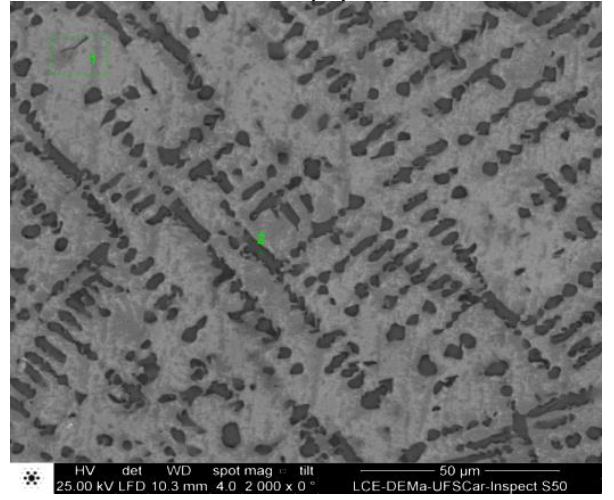

(c)

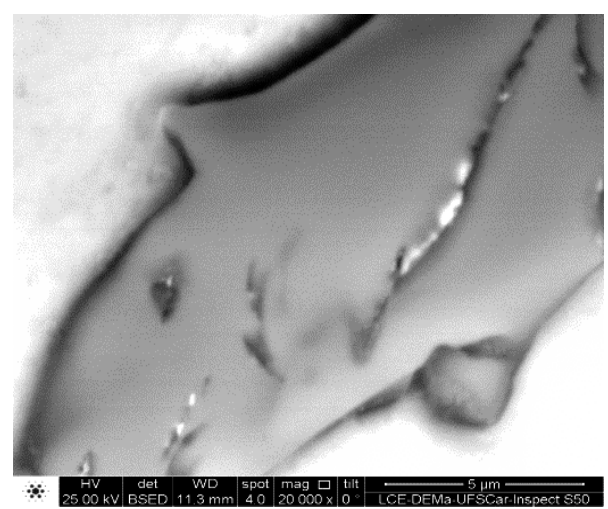

(b)

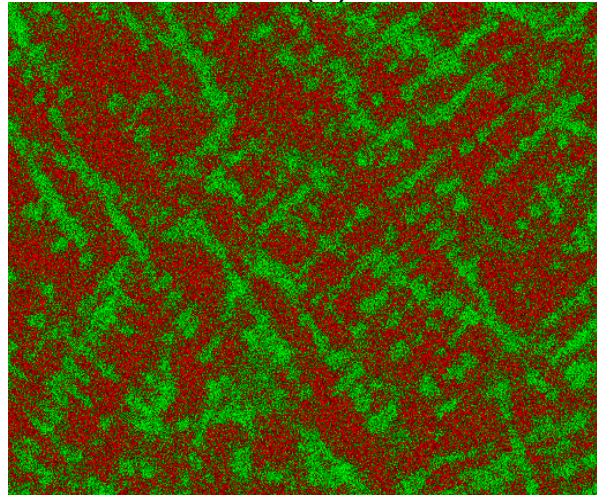

(d)

Figura 2. Microscopia eletrônica de varredura da liga Ti-40Nb (at.\%) após fusão a arco (a, b) ataque com solução de $3 \% \mathrm{HF}, 30 \% \mathrm{HNO}_{3}$ e água destilada, (c, d) mapa de composição química, em que a

cor vermelha indica a presença do Nióbio e a cor verde indica a presença do Titânio. A região dendrítica (1) apresentou 74,66 at.\% Ti e 25,34 at.\% Nb e a região interdendrítica (2) apresentou 56,21 at.\% Ti e 43,79 at. $\%$ Nb. 
Nas regiões interdendríticas ocorreu a segregação do Nióbio (regiões em vermelho da figura 2d), elemento este que estabiliza a fase $\beta$ de interesse para a hidrogenação. Na figura 2a é possível visualizar alguns contornos da fase $\beta$ nas regiões com coloração cinza claro existentes entre as dendritas. Os resultados de EDS mostraram que o interior da dendrita é mais rico em Titânio $(75,1 \pm 0,6$ at.\%) e, portanto, empobrecido em Nióbio (24,9 \pm 0,6 at.\%), ao contrário das regiões interdendríticas onde o Nióbio segregou e cujo percentual médio caracterizado foi de $53,6 \pm 2,1$ at. $\% \mathrm{Nb}$. No interior de algumas dendritas (figura $2 b$ ) foi possível observar contornos de fase com morfologia acicular, similar à fase $\alpha$ " que se forma na faixa de composição química entre 11 e 28 at.\% Nb por aplicação de resfriamento rápido [7]. O percentual de Nióbio no interior das dendritas via EDS possibilitou estimar [8] uma média para a temperatura de início de reação martensítica (Ms) igual a $313 \pm 21^{\circ} \mathrm{C}$. Os resultados de DRX exibidos nas figuras 3,4 e 5 revelam também que a fase $\beta$ (CCC) se transforma em uma fase hidreto, com a estrutura cristalina cúbica de face centrada (CFC) após o período de hidrogenação. Os contornos de grãos e de fases destas amostras são locais preferenciais para a difusão do hidrogênio, contudo a presença da fase $\alpha$ (HCP) durante a hidrogenação promove a formação de hidretos de elevadas temperaturas de dessorção (520 a $610{ }^{\circ} \mathrm{C}$ ) [4], devido à sua estabilidade termodinâmica.

Após dessorção via DSC foi possível observar que a microestrutura $\beta+\alpha$ " voltou a ser formada ao término do resfriamento a $40{ }^{\circ} \mathrm{C} / \mathrm{min}$ a partir do campo $\beta\left(600{ }^{\circ} \mathrm{C}\right)$. Dados sobre a hidrogenação da fase $\alpha(\mathrm{HCP})$ do sistema Ti-Nb são encontrados na literatura [4]. A absorção de hidrogênio das fases metaestáveis $\alpha$ ', $\alpha$ " e $\omega$ do sistema TiNb não vem recebendo atenção na literatura, não tendo ficado claro neste trabalho o comportamento em hidrogenação da fase de estrutura ortorrômbica $(\alpha ")$ visualizada nas figuras 3,4 e 5 . O hidreto CFC formado a partir da fase $\beta$ é o $\mathrm{Ti}_{0,6} \mathrm{Nb}_{0,4} \mathrm{H}_{1,8}$, cuja capacidade de armazenamento de hidrogênio no estado sólido é de 2,87 p\% e cuja temperatura de dessorção é igual a $360^{\circ} \mathrm{C}$ [4].

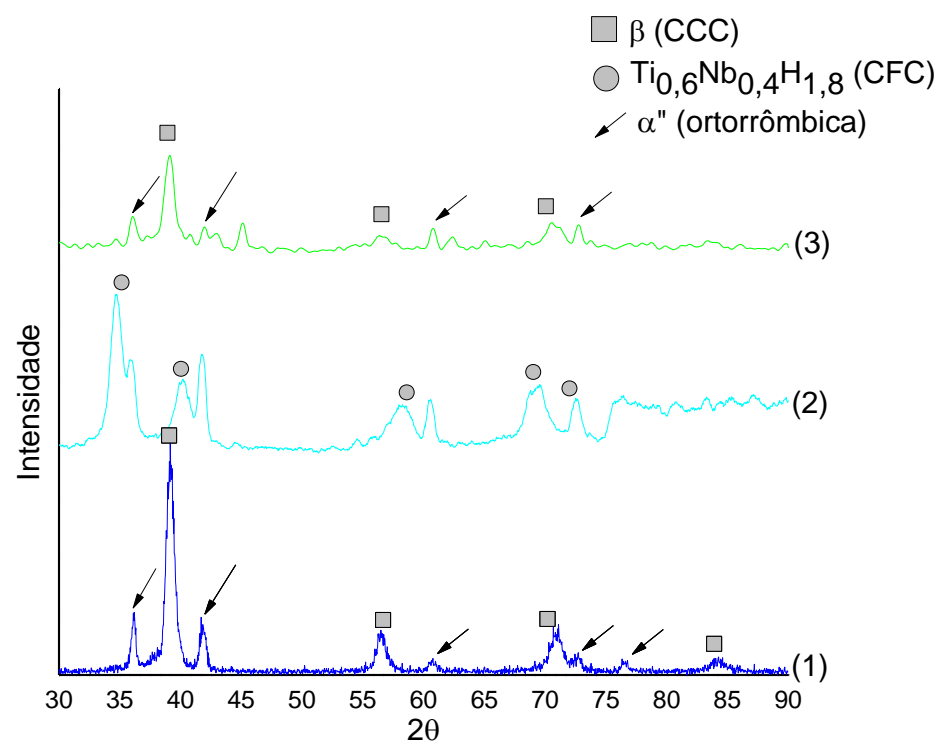

Figure 3. Difração de Raios X (1) amostra FA, (2) amostra FA após absorção a $300^{\circ} \mathrm{C}$ e (3) após dessorção via DSC $\left(600^{\circ} \mathrm{C}, 10^{\circ} \mathrm{C} / \mathrm{min}\right)$ 


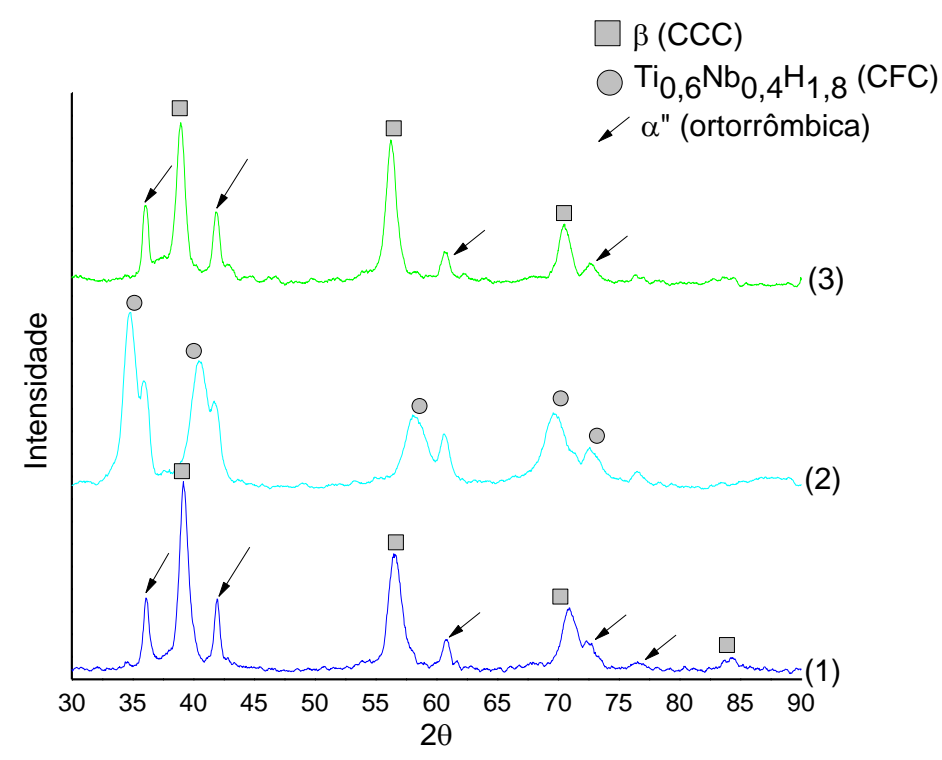

Figure 4. Difração de Raios X (1) amostra CR40, (2) CR40 após absorção em temperatura ambiente, (3) após dessorção via DSC $\left(600^{\circ} \mathrm{C}, 10^{\circ} \mathrm{C} / \mathrm{min}\right)$

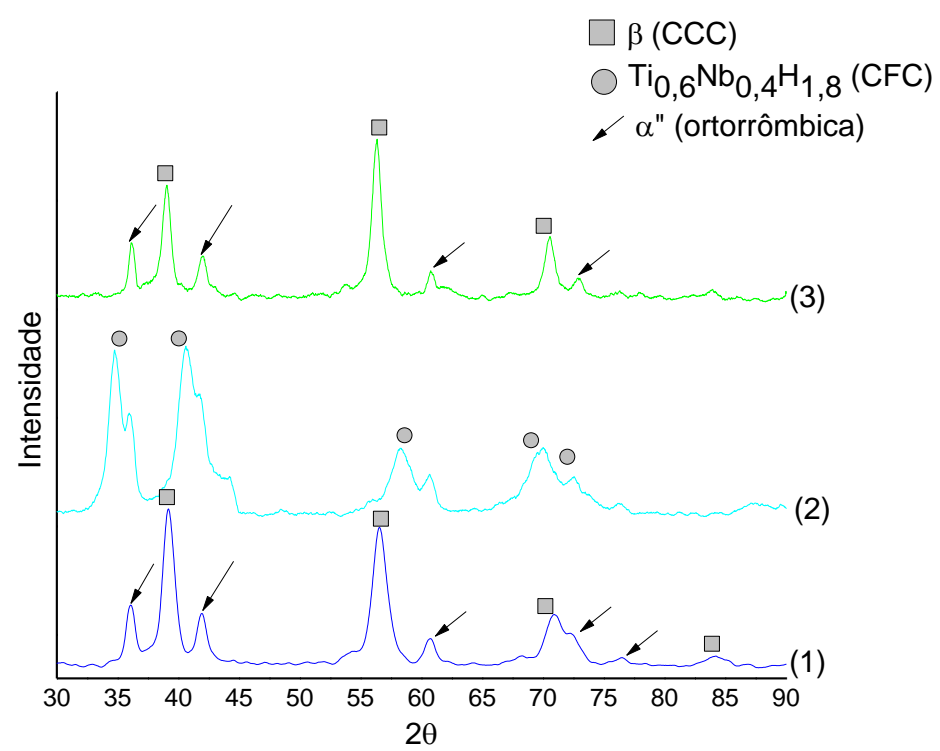

Figure 5. Difração de Raios X (1) amostra CR80, (2) CR80 após absorção em temperatura ambiente, (3) após dessorção via DSC $\left(600^{\circ} \mathrm{C}, 10^{\circ} \mathrm{C} / \mathrm{min}\right)$

Em acordo com os resultados mostrados na figura 6 , a estabilidade térmica das fases metaestáveis foi avaliada à medida que a liga Ti-40Nb foi aquecida até 1000 ${ }^{\circ} \mathrm{C}$ a uma taxa de $10{ }^{\circ} \mathrm{C} / \mathrm{min}$, o que deu condições para que as transformações de fases ocorressem. No geral a transformação martensítica de $\alpha$ ' para $\alpha$ libera energia térmica, enquanto a transformação de $\alpha$ para $\beta$ é endotérmica [13]. Durante o aquecimento a fase martensítica $\alpha$ " se transforma endotermicamente para a fase $\beta$ metaestável através dos mecanismos de transformações martensíticas reversíveis citados na literatura $[3,13]$. A fase $\beta$ metaestável, com a sequência do aquecimento, se decompõe em regiões enriquecidas e empobrecidas em Nióbio, sendo caracterizado por um efeito exotérmico na curva de DSC. As fases $\alpha$ e $\beta$ estáveis podem ser formadas a partir desta decomposição de fase $\beta$ metaestável. Formada a 
partir das regiões empobrecidas em Nióbio, a fase $\alpha$ se transformará em $\beta$ estável em temperaturas mais elevadas, com a continuidade do aquecimento [13]. Em acordo com os resultados de EDS as dendritas do material como fundido apresentam composição química heterogênea, o que promoveu diferentes faixas de temperaturas a partir das quais a fase $\alpha$ " se decompõe para $\alpha$ e $\beta$ metaestável. $\mathrm{Na}$ figura 6, até $600{ }^{\circ} \mathrm{C}$, é possível ver um grande efeito exotérmico devido à decomposição da fase $\beta$ metaestável. Este efeito exotérmico, à medida que ocorre simultaneamente com a decomposição da fase $\alpha$ ", encobre parte dos efeitos endotérmicos devido à transformação de $\alpha$ " para $\beta$ metaestável saturado em Nióbio e $\alpha$ estável. Os efeitos da aplicação da laminação a frio foram significativos. À medida que o número de passes aumenta, introduzindo maior deformação, foi observado que o efeito exotérmico devido à decomposição da fase $\beta$ metaestável tornou-se mais intenso. Em contrapartida, os efeitos endotérmicos da decomposição da fase $\alpha$ " tornaram-se mais difusos. Contudo, a laminação antecipou para temperaturas mais baixas os efeitos térmicos das decomposições das fases $\beta$ metaestável e $\alpha$ ".

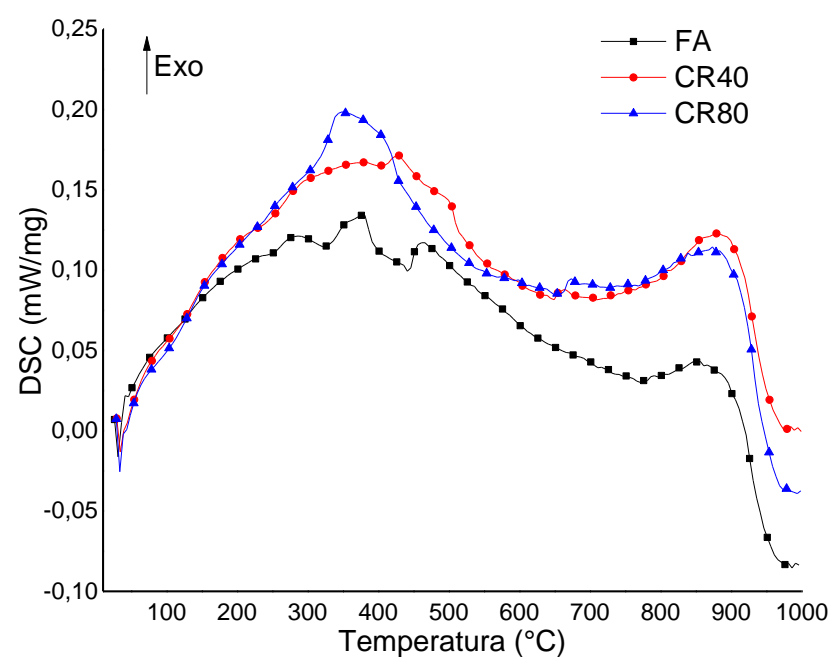

Figura 6. Resultados de DSC do lingote fundido a arco (FA) e após 40 (CR40) e 80 (CR80) passes de laminação a frio.

Os resultados obtidos via DSC, na tabela 1, mostram que as temperaturas de início de dessorção do hidreto foram significativamente influenciadas pelo número de passes adotado durante a laminação a frio da liga fundida. Para as amostras laminadas os resultados após absorção, em temperatura ambiente por até $2 \mathrm{~h}$, correspondem de 62 a $68 \%$ da capacidade máxima de armazenamento da liga $(2,87 \mathrm{p} \%)$ citado na literatura [4]. Os resultados exibidos na tabela 1 para os pós de Titânio e Nióbio puros e para a liga Ti-40Nb estão em acordo com a literatura [4, 5]. Quanto às discrepâncias de valores observados, quando comparadas as capacidades atingidas obtidas através dos registros no aparato de Sievert com os resultados de TGA, elas são possivelmente devido à oxidação do Titânio o que promove ganhos de massa durante a análise no STA. No entanto os resultados de TGA exibidos na tabela 1 são perfeitamente comparativos. As largas faixas de temperaturas de dessorção do hidrogênio, observadas na tabela 1, são creditadas à presença de outras fases que formam hidretos mais estáveis do que o hidreto 
formado a partir da fase $\beta$ e às heterogeneidades de composição química das fases. Cabe ressaltar que quanto maior o teor de Titânio da fase, mais estável será o hidreto e maiores serão as temperaturas necessárias para a dessorção [4], tal como é mostrado na tabela 1, sendo que a amostra hidrogenada de Titânio puro apresenta a maior área abaixo da curva de DSC, portanto, a entalpia de formação mais negativa. Quando comparamos a amostra fundida com as laminadas é possível observar uma redução da estabilidade do hidreto formado devido à introdução da deformação. A consequência disto é a redução das temperaturas de início da dessorção, possivelmente associadas aos hidretos formados a partir da fase $\beta$. As temperaturas de pico e principalmente as de final da dessorção não foram significativamente influenciadas pela laminação, estando as temperaturas finais de dessorção possivelmente associadas aos hidretos formados a partir da fase $\alpha$.

Tabela 1. Propriedades de absorção e dessorção de Hidrogênio caracterizadas via dados obtidos no aparato volumétrico tipo Sievert e via análises acopladas de DSC e TGA

\begin{tabular}{|c|c|c|c|c|c|c|c|c|c|}
\hline \multirow{3}{*}{ Amostras } & \multirow{2}{*}{\multicolumn{4}{|c|}{$\begin{array}{c}\text { Aparato volumétrico tipo } \\
\text { Sievert }\end{array}$}} & \multicolumn{5}{|c|}{ STA-449C } \\
\hline & & & & & \multicolumn{4}{|c|}{ DSC } & \multirow[b]{2}{*}{$\begin{array}{l}\text { TGA } \\
(\%)\end{array}$} \\
\hline & $\begin{array}{c}t \\
(h)\end{array}$ & $\begin{array}{c}\mathrm{T} \\
\left({ }^{\circ} \mathrm{C}\right)\end{array}$ & $\begin{array}{l}\mathrm{P}_{\mathrm{H} 2} \\
\text { (bar) }\end{array}$ & $\begin{array}{c}\text { wt. } \% \\
\mathrm{H}_{2}\end{array}$ & $\begin{array}{l}\text { Início } \\
\left({ }^{\circ} \mathrm{C}\right)\end{array}$ & $\begin{array}{l}\text { Pico } \\
\left({ }^{\circ} \mathrm{C}\right)\end{array}$ & $\begin{array}{l}\text { Final } \\
\left({ }^{\circ} \mathrm{C}\right)\end{array}$ & $\begin{array}{l}\text { Área } \\
(\mathrm{J} / \mathrm{g})\end{array}$ & \\
\hline $\begin{array}{c}\text { Titânio } \\
\text { puro }\end{array}$ & \multirow{3}{*}{15} & \multirow{3}{*}{300} & \multirow{5}{*}{20} & 4,01 & 455 & 556 & 586 & 1967 & $-2,31$ \\
\hline $\begin{array}{l}\text { Nióbio } \\
\text { puro }\end{array}$ & & & & 1,08 & 533 & 549 & 564 & 291 & $-0,55$ \\
\hline $\begin{array}{c}\text { Liga } \\
\text { (Fundido) }\end{array}$ & & & & 2,14 & 309 & 329 & 531 & 773 & $-1,89$ \\
\hline $\begin{array}{l}\text { Laminado } \\
\text { (40 passes) }\end{array}$ & \multirow{2}{*}{$\begin{array}{l}\text { Até } \\
2 \mathrm{~h}\end{array}$} & \multirow{2}{*}{25} & & 1,77 & 301 & 318 & 549 & 375 & $-1,14$ \\
\hline $\begin{array}{l}\text { Laminado } \\
\text { (80 passes) }\end{array}$ & & & & 1,95 & 260 & 304 & 534 & 594 & $-1,37$ \\
\hline
\end{tabular}

$\mathrm{t}=$ tempo, $\mathrm{T}=$ temperatura, $\mathrm{P}_{\mathrm{H} 2}=$ pressão de hidrogênio

De acordo com os dados expostos na tabela 2 os ganhos cinéticos, associados à redução de tempo para atingir a fração transformada $(\phi)$ de 0,90 , foram significativos à medida que o número de passes aumenta de 40 para 80 . De fato, os efeitos da aplicação da deformação plástica severa são importantes para cinética de absorção de hidrogênio dos diversos metais e ligas destinados à armazenagem de hidrogênio $[14,15]$. Este tempo de absorção de hidrogênio para a fração transformada $\phi=0,90$ é reduzido em 19,4\% até 92,9\% quando comparamos a amostra como fundida com as amostras laminadas com 40 e 80 passes, respectivamente. Isto é devido à introdução de um maior grau de deformação associado com a manutenção do tamanho de cristalito em escala nanométrica e à introdução de trincas.

Tabela 2. Tamanho de cristalito e microdeformações obtidas através dos gráficos de Williamson Hall (W-H) e o tempo necessário para atingir a fração transformada de hidreto igual a 0,9

\begin{tabular}{|c|c|c|c|c|}
\hline \multirow{2}{*}{ Fase $\boldsymbol{\beta}$} & $\mathbf{t}(\mathbf{n m})$ & \multicolumn{2}{|c|}{$\mathbf{W}-\mathbf{H}$} & $\phi=\mathbf{0 , 9 0}$ \\
\cline { 3 - 5 } & $\mathbf{( 0 1 1 )}$ & $\mathbf{t}(\mathbf{n m})$ & $\mathbf{e}$ & $\mathbf{t e m p o}(\mathbf{m i n})$ \\
\hline FA & 12,25 & 11,12 & 0,41 & 108 \\
\hline CR40 & 15,52 & 18,76 & 0,71 & 87 \\
\hline CR80 & 12,67 & 23,85 & 0,90 & 7,6 \\
\hline
\end{tabular}




\section{CONCLUSÃO}

As mudanças microestruturais promovidas pela laminação a frio em atmosfera de $\mathrm{Ar}$ ativaram mecanicamente a liga fundida Ti-40 Nb (at.\%) após 80 passes tendo sido possível atingir $68 \%$ da capacidade de armazenamento da liga após $12 \mathrm{~min}$ de hidrogenação em temperatura ambiente.

A introdução da deformação devido à realização da deformação plástica severa tornou mais intensos os efeitos exotérmicos da decomposição da fase $\beta$ metaestável saturada em $\mathrm{Nb}$. Contudo, os efeitos desta decomposição nas absorções de Hidrogênio realizadas em temperaturas mais elevadas $\left(300^{\circ} \mathrm{C}\right)$ precisam ser melhor investigados.

A energia armazenada devido à laminação a frio ao promover um maior afastamento do equilíbrio da fase $\beta$ metaestável saturada em $\mathrm{Nb}$, devido à introdução de defeitos cristalinos, favoreceu a formação da fase hidreto a uma rápida cinética de absorção de hidrogênio em temperatura ambiente $\left(25^{\circ} \mathrm{C}\right)$.

A fase $\beta$, de interesse para o armazenamento de hidrogênio no estado sólido, se transforma na fase hidreto (CFC). A microestrutura volta a ser majoritariamente constituída pelas fases $\beta$ (CCC) e $\alpha$ " (ortorrômbica) após a dessorção.

A dessorção dos hidretos da liga $\mathrm{Ti}-40 \mathrm{Nb}$ ocorre em uma ampla faixa de temperaturas (260 a $549{ }^{\circ} \mathrm{C}$ ), sendo influenciada pela microestrutura inicial que hidrogenou e pela aplicação de deformação.

\section{Agradecimentos}

Os autores são gratos pelo suporte financeiro do CNPq e da FAPESP (Projeto Temático 2013/05987-8)

\section{REFERÊNCIAS}

1 Kent D, Wang G, Dargusch M. Effects of phase stability and processing on the mechanical properties of Ti-Nb based $\beta$ Ti alloys. J Mech Behav Biomed Mater. 2013;28:15-25.

2 Pathak A, Banumathy S, Sankarasubramanian R, Singh AK. Orthorhombic martensitic phase in Ti-Nb alloys: A first principles study. Comput Mater Sci. 2014;83:222-228.

3 Tahara M, Kim HY, Inamura T, Hosoda H, Miyazaki S. Role of interstitial atoms in the microstructure and non-linear elastic deformation behavior of Ti-Nb alloy. J Alloys Compd. 2013;577(SUPPL. 1):S404-407.

4 Aleksanyan AG, Dolukhanyan SK, Shekhtman VS, Khasanov SS, Ter-Galstyan OP, Martirosyan MV. Formation of alloys in the Ti-Nb system by hydride cycle method and synthesis of their hydrides in self-propagating high-temperature synthesis. Int $\mathrm{J}$ Hydrogen Energy. 2012;37(19):14234-14239.

5 Ruz P, Kumar A, Banerjee S, Meena SS, Pillai CGS. Hydrogen absorption characteristics and Mössbauer spectroscopic study of Ti0.67Nb0.33-xFex ( $x=0.00$, $0.13,0.20)$ alloys. J Alloys Compd. 2014;585:120-128.

6 Murray JL. Nb-Ti (Niobium-Titanium), binary alloy phase diagrams.II Ed., Ed. T.B. Massalski. 1990 [acesso em 09 set. 2015];3;2775-2778. Disponível em:http://www1.asminternational.org/ asmenterprise/APD/ViewAPD.aspx?id=901726.

7 Zhang Y, Liu H, Jin Z. Thermodynamic assessment of the Nb-Ti system. Calphad Comput Coupling Phase Diagrams Thermochem. 2001;25(2):305-17. 
8 Tobe H, Kim HY, Inamura T, Hosoda H, Nam TH, Miyazaki S. Effect of Nb content on deformation behavior and shape memory properties of Ti-Nb alloys. J Alloys Compd. 2013;577(SUPPL. 1):S435-438.

9 Fallah V, Amoorezaei M, Provatas N, Corbin SF, Khajepour A. Phase-field simulation of solidification morphology in laser powder deposition of Ti-Nb alloys. Acta Mater. 2012;60(4):1633-1646.

10 Varin RA, Czujko T,WronskiZS. Nanomaterials for Solid State Hydrogen Storage Fuel Cells and Hydrogen Energy. Springer; 2009

11 de Keijser TH, Langford JI, Mittemeijer EJ, Vogels ABP. Use of the Voigt function in a single-line method for the analysis of $X$-ray diffraction line broadening. J Appl Crystallogr. 1982;15(Copyright 1982, IEE):308-314.

12 de Keijser TH, Mittemeijer EJ, Rozendaal HCF. The Determination of Crystallite-Size and Lattice-Strain Parameters in Conjunction with the Profile-Refinement Method for the Determination of Crystal Structures. J Appl Crystallogr. 1983;16:309-316.

13 Matlakhova LA, Matlakhov AN, Monteiro N, Fedotov SG. Influence of Temperature on the Properties and Phase Transformations in Ti-Nb Alloys with $2 \%$ Al. Revista Matéria. 2006;11:41-47.

14 Floriano R, Leiva DR, Carvalho JA, Ishikawa TT, Botta WJ. Cold rolling under inert atmosphere: A powerful tool for Mg activation. Int J Hydrogen Energy. Elsevier Ltd; 2014;39(10):4959-4965.

15 Asselli AAC, Leiva DR, Huot J, Kawasaki M, Langdon TG, Botta WJ. Effects of equalchannel angular pressing and accumulative roll-bonding on hydrogen storage properties of a commercial ZK60 magnesium alloy. Int J Hydrogen Energy. Elsevier Ltd; 2015;40(47):16971-16976. 